\title{
O FUTURO DA DEMOCRACIA: GOVERNO DIGITAL
}

Nossas vidas já não podem mais ser dissociadas da tecnologia. Desde o início da década de 1990, quando apareceram os primeiros vestígios do famoso "www" (World Wide Web), estamos vivendo uma nova forma de comunicação, baseada numa rede digital de dados complexa e difusa: a internet.

Confesso que eu ainda tenho alguma dificuldade em expressar-me na sua linguagem, o que, acredito, seja mais ou menos comum entre a minha geração, a que já passou dos cinquenta! Portanto, para escrever este capítulo sem deslizes, contei com o apoio inspirador de um jovem assessor jurídico do tribunal de contas tocantinense, antenado e estudioso, que eu não poderia deixar de nominar, João Paulo Landim Macedo, que pacientemente me ouve, me elucida e me coloca no prumo sempre que o assunto beira o universo digital. E assim somamos a experiência da maturidade com o arrojo da jovialidade.

Controvérsias à parte sobre os malefícios à saúde comportamental ou ao convívio interpessoal, o fato é que os meios tecnológicos estão cada vez mais inseridos no cotidiano das pessoas. Ou alguém despido do aparelho celular por um dia não se sentiria um náufrago, alijado do mundo? Um texto motivacional publicado no Facebook, uma foto da última viagem no Instagram, ou uma queixa sobre o último escândalo público no Twitter, são manifestações de um mundo $100 \%$ conectado, que não consegue mais abrir mão da velocidade, proximidade e interatividade proporcionadas pela rede digital. A rapidez e a leveza, a propósito, estão entre as seis propostas para o próximo milênio, de Ítalo Calvino. ${ }^{321}$

321 CALVINO, Ítalo. Seis propostas para o próximo milênio. São Paulo: Companhia das Letras, 1990. 
-• Finanças públicas: travessia entre o passado e o futuro

Estas novas tecnologias de informação deram uma cara nova aos indivíduos e grupos sociais, fazendo surgir a assim denominada sociedade de informação. ${ }^{322}$

A internet então se converte em um dos mais poderosos, promissores e perigosos instrumentos da globalização de nossa época. Nas palavras de Rosanvallón, consiste em um formato social que dá uma voz audível à difusa opinião pública, mas que se revela ao mesmo tempo com um caráter monstruoso, multiforme, contraditório, aonde se misturam os rumores mais insensatos e os papéis mais reflexivos. ${ }^{323}$

Com efeito, essa revolução digital não deixou de exercer uma forte repercussão sobre a ordem política e governamental. É curioso observar que as sucessivas inovações técnicas de comunicação, informação e linguagem humanas sempre estiveram associadas às formas de organização política. O surgimento da escrita nos hieróglifos dos fenícios relaciona-se à ascensão das primeiras formações sociais hierarquizadas que remetem ao conceito de Estado; o aparecimento do alfabeto, na Grécia antiga, é contemporâneo aos primórdios da democracia, quando a leitura se torna acessível à maioria dos habitantes da pólis. Adiante, com a aparição dos veículos de imprensa e a consequente difusão ampla de ideias, dando suporte à opinião pública, vê-se o surgimento das democracias modernas. E assim, sucessivamente, o cinema, o rádio, a televisão, o telefone-celular, tudo paralelo ao desenvolvimento das relaçôes políticas, cada vez mais reivindicadas para se tornarem visíveis e acessíveis. ${ }^{324} \mathrm{Na}$ lição de Giovanni Sartori, ao se dirigir à sociedade televisionada que virava a esquina do século XX ao século XXI, a cada incremento de demo-poder deveria corresponder-lhe um incremento de demo-saber. ${ }^{325}$

A internet revolucionou tudo o que encontrou pelo caminho, da imprensa ao varejo. Seria estranho se também não revolucionasse o Estado. ${ }^{326}$ É inquestionável, portanto, o impacto substancial que o desenvolvimento das tecnologias teve (e tem) nos fins e no funcionamento das instituições de Estado, moldando novíssimos

322 CASTELLS, A. Sociedade em rede. Tradução de Roneide Venâncio Majer. São Paulo, Paz e Terra, 2000.

323 ROSANVALLÓN, Pierre. El buen gobierno. Buenos Aires: Manantial, 2015.

${ }^{324}$ GUZZI, Drica. Web e participação: a democracia no século XXI. Escola do Futuro, Senac Editoras, 2010.

325 SARTORI, Giovanni. Homo videns. La sociedad teledirigida. Buenos Aires: Alfaguara, 1998.

326 MICKLETHAWAIT, John; WOOLDRIDGE, Adrian. A quarta revolução: a corrida global para reinventar o estado. Tradução de Afonso Celso da Cunha Serra. Ed. Portfolio-Penguin, 2015, p. 88. 
paradigmas nas relações sócio-políticas. As formas progressivamente abertas de comunicação acabam balançando as estruturas historicamente fechadas do governo, ao acelerar à décima potência o fluxo de informações, reduzindo então as barreiras para o florescimento de ações coletivas. Enfim, a internet representa uma oportunidade de amadurecimento democrático, que reforça a musculatura cívica, renovando as possibilidades de mobilização em espaços que antes eram impermeáveis à ação cidadã.

O crescente número de manifestaçôes civis expressivas organizadas no seio das redes digitais, desde 1994, com o caso dos zapatistas mexicanos ocupando prefeituras em reivindicação à reforma agrária, até a onda de protestos em favor da democracia, em 2011, nos países do Oriente Médio (Egito, Tunísia, Líbia), conhecida como Primavera Árabe e as passeatas brasileiras de junho de 2013, demonstram a força incontrastável dos novos meios de cidadania tecnológica.

Hoje, a esmagadora maioria das pessoas tem às mãos um instrumento poderoso de engajamento - o celular, onde as possibilidades de ação política por parte da esfera civil são praticamente infinitas: realiza-se denúncias, como através do aplicativo Dilo Aqui, desenvolvido em Honduras; decide-se sobre alocações orçamentárias em projetos comunitários, como pelo dispositivo Open City Hall, em Salt Lake City (EUA); financia-se campanhas eleitorais através das "vaquinhas" eletrônicas (crowdfunding), nos termos do art. 23, $\$ 4^{\circ}$, IV, da Lei n. 13.488/2017; opina-se sobre a qualidade dos serviços públicos, como por meio do aplicativo Get it Done, da prefeitura de San Diego (EUA); inicia-se propostas legislativas populares, como através do aplicativo brasileiro Mudamos, e até recebe-se premiaçōes ou notas pela participação interativa, a exemplo do aplicativo desenvolvido na municipalidade de Manor (Texas, EUA), que concede pontuaçôes digitais para engajar cidadãos a contribuir com propostas de política pública numa plataforma digital. Os indivíduos podem acessar sua pontuação no sítio eletrônico da cidade e trocá-los por vantagens. ${ }^{327}$

O ponto essencial aqui é entender que estas novas ferramentas viabilizaram um verdadeiro processo de ressignificação da esfera pública, emergindo a figura do governo eletrônico, ${ }^{328}$ também denominado como e-government, democracia digital ou e-gov, para os íntimos.

327 GASTIL, J.; RICHARDS, R. Embracing digital democracy: a call for building an online civic commons. PS: Political Science \& Politics, 50, p. 758-763, 2017.

${ }^{328}$ Segundo Ferrer, trata-se do conjunto de serviços e acesso a informações que o governo oferece aos diferentes atores da sociedade civil por meios eletrônicos. FERRER, Florência. A importância do governo eletrônico no Brasil. Valor Econômico. São Paulo, mar. 2003. 
E o paradigma do governo aberto, ao qual já me referi anteriormente, deve conspirar com estes canais e ferramentas proporcionados pela democracia digital. Numa perspectiva de Estado, enquanto a abertura diz respeito à disponibilidade do governo, a tecnologia refere-se ao acesso. Isso quer dizer que ambas as esferas se complementam para uma nova forma de fazer política ou de agir politicamente, dando ensejo ao modelo que a OCDE chamou de governo de dados abertos (open government data). $\mathrm{O}$ uso dos dispositivos e tecnologias digitais serviria para reforçar, auxiliar e corrigir diversos aspectos tradicionais da prática governamental.

É certo que as mudanças provocadas pela revolução dos meios de comunicação digital não suscitaram apenas visões progressistas ou otimistas, como a que lhes pretendo apresentar, senão também despertou prognósticos extremamente céticos e, por vezes, catastróficos. Sartori, por exemplo, acreditava que a preponderância do visível (ou televisível) sobre o inteligível levar-nos-ia a ver sem entender, gerando desinformação e uma profunda atrofia cultural nos indivíduos modernos, os quais chama de Homo Videns, transfiguração do Homo Sapiens, produto da cultura escrita. ${ }^{329} \mathrm{O}$ receio de que os meios digitais conduzissem a um tipo de tecnocracia controladora, deu azo ainda a prediçôes ficcionais segundo as quais o governo se converteria em um grande irmão eletrônico, ou que os dispositivos eletrônicos funcionassem como um olho do poder, na expressão de Michel Foucault, que espiona a todos e é dirigido por um grupo restrito de elites. ${ }^{330}$

Outros diagnósticos abordam os potenciais riscos à democracia subsequentes à expansão das redes sociais e de informação. Os mais iminentes deles dizem respeito ao aprofundamento da polarização política, sobre o qual já falamos em tópico anterior, e a proliferação de notícias falsas (fake news), reduzindo a habilidade do cidadão comum de distinguir, num volume gigantesco de dados, aquelas que são confiáveis e as que são inverídicas, prejudicando ainda o conhecimento sobre os assuntos públicos, essencial à qualidade do regime.

A despeito das impressóes e prognósticos mais incrédulos, me filio àqueles que veem na internet um manancial de oportunidades democráticas. Obviamente, a internet não solucionará as questôes sociais mais prementes na agenda política brasileira, tampouco realizará de vez as promessas não cumpridas da democracia, mas constitui um importante instrumento à disposição dos atores sociais. Se utilizada com sabedoria, as redes digitais oferecem possibilidades concretas de melhoramento da governança. Segundo a OCDE, a agenda de reformas do setor público

329 SARTORI, Giovanni. Homo videns. La sociedad teledirigida. Buenos Aires: Alfaguara, 1998.

330 NEGROPONTO, Nicholas. Being digital. Nova York: Knopf, 1995. 
poderia contribuir para a criação de um ambiente político favorável para associar o uso das tecnologias digitais e dados governamentais como vetor de integridade no governo. ${ }^{331}$ Bingo!

Aliás, é crescente o número de estudos acerca da influência extremamente positiva dos mecanismos tecnológicos na qualidade das instituições governamentais, sobretudo nas dimensões que assentamos como alicerces do contexto de governança aberta: transparência, envolvimento do povo e accountability. Iria além, pois entendo que esta modernização é condição necessária ao desenvolvimento da ação coletiva que promova integridade e contenha a corrupção na sociedade. ${ }^{332}$

De igual modo, a latente crise de representatividade e desconfiança na gestão dos interesses públicos, pelos agentes políticos, conforme extensamente abordado neste livro, coloca em evidência a necessidade de meios que estreitem a relação da sociedade com os seus governos. Não hesito em dizer que as inovações digitais podem fornecer os materiais que preencha esse vácuo, aprimorando a interação dos atores nos processos decisórios, o que reforça a legitimidade do contrato social e reconstrói alguma forma de capital social.

Entretanto, como aquelas dimensões democráticas podem ser realçadas por este novo e-gov, para conduzir-nos ao contexto institucional de integridade?

No campo da transparência, a tecnologia permite oferecer ao cidadão um armazém adequado de informações confiáveis e relevantes sobre as ações e serviços do governo. A produção de dados em formato aberto, isto é, que não sofrem controle exclusivo e podem ser livremente utilizados, reutilizados e distribuídos, por qualquer um, em qualquer lugar, por qualquer dispositivo, constitui um ativo público que reduz a assimetria de informação. Hoje, não há qualquer desculpa para que os assuntos públicos sejam conduzidos alheios ao conhecimento do público. ${ }^{333}$

No aspecto participativo, os mecanismos digitais fornecem oportunidades fáceis e de baixo custo para um engajamento difuso (indiscriminado) e direto (desintermediado), na tomada de decisões e na definição da agenda política. Ao superar os limites de tempo e espaço que emperraram as possibilidades de participação direta da população no ciclo das políticas públicas (definição, formulação, decisão,

331 OECD. Compendium of good practices on the publication and reuse of open data for anticorruption across G20 countries: towards data-driven public sector integrity and civic auditing, 2016.

332 O Relatório de Desenvolvimento Mundial, de 2017, formulado pelo Banco Mundial, reforça esta ideia ao pregar a indispensabilidade das redes sociais e da internet para o empoderamento cidadão e à ação coletiva. (Banco Mundial. Relatório de Desenvolvimento Mundial, 2017).

333 WILSON GOMES: Internet e participação política em sociedades democráticas. Revista Famecos, Porto Alegre, n. 27, 2005. 
implementação e avaliação), as tecnologias de comunicação e informação permitem expandir quase que ilimitadamente o número de vozes que podem ser ouvidas na arena de debate político, reduzindo o déficit democrático e aperfeiçoando o sistema de governança. ${ }^{334}$ A propósito, Bobbio foi certeiro ao afirmar que o progresso da democracia não estava mais atrelado à questão do sufrágio, mas aos espaços nos quais pode-se exercer o direito de participação, e a internet atua justamente na ampliação deste espaço. ${ }^{335}$

Para mais, a vasta rede de oportunidades desvelada pelos canais digitais substitui o tradicional modelo de participação "sob solicitação" (upon-request), pelo qual as pessoas são requestadas a participar apenas quando as autoridades públicas pedem, por uma dimensão "sob demanda" (on-demand), onde os cidadãos não precisam esperar por um convite para contribuir, mas o fazem de maneira independente, conforme as suas necessidades.

Finalmente, na ótica do accountability, nos referimos à perspectiva da qualidade da performance governamental e como ela é avaliada ou fiscalizada pelos cidadãos. Esta abordagem do accountability centrada no desempenho governamental se distancia dos tradicionais tratamentos sancionatórios do dever de redenção de contas, e será objeto de explicação em capítulo próprio. Aqui, é suficiente perceber que o governo eletrônico e os novos dispositivos digitais podem reforçar o sentido de responsabilidade e responsividade do poder público, porquanto possibilitam aos governos conhecer com maior precisão as demandas dos cidadãos, e a estes saber se e como as metas ou indicadores estão sendo satisfeitos em nível nacional, regional e local. Reduz-se assim os incentivos para agir com particularismo, concedendo privilégios em nome da corrupção, ao passo que se enrijece a capacidade coletiva de controle social, de pressão por explicações e correção de ações ineficientes ou desonestas.

Não se trata, como se pode notar, de um simples projeto de facilitação por intermédio da tecnologia, transferindo serviços burocráticos para plataformas digitais, mas de uma transformação da forma como as autoridades públicas trabalham e se relacionam com seus stakeholders, a sociedade civil.

De fato, este novo formato digital de governo contrapõe-se tanto ao modelo de gestão racional-burocrático weberiano, como ao próprio estereótipo da administração gerencial, cujo alicerce está no tratamento do cidadão como consumidor de

334 Idem, p. 331.

335 BOBBIO, Norberto. O futuro da democracia: uma defesa das regras do jogo. Tradução de Marco Aurélio Nogueira. 6. ed. Rio de Janeiro: Paz e Terra, 1986, p. 27 
serviços, evoluindo para uma noção societal do setor público, que busca engajar o maior número possível de cidadãos nos assuntos públicos, para que este não se limite à clientela, mas seja um verdadeiro coautor das ações estatais.

Contudo, esta estrutura ideal de uso da tecnologia não prescinde de uma mudança também no comportamento dos atores públicos, para que reconheçam que a esfera civil tem algo a dizer e pode (e deve) influenciar positivamente decisões políticas que digam respeito aos seus próprios interesses. É necessário que todos discutam o que significa governar no século XXI, e que desafios devem ser superados para que a revolução digital realmente consiga mudar o contexto institucional.

Por isso, impõe-se aos governos, em todos as suas esferas, a missão de canalizar os meios e métodos digitais que permitam o exercício efetivo da governança eletrônica, em benefício da legibilidade e responsabilidade de suas ações, bem como do engajamento mais intenso do povo. Através de ferramentas que sejam acessíveis, simples e inteligíveis, o Estado convoca o cidadão à governança cooperativa.

Apesar da inequívoca expansão global do acesso à internet e, particularmente, dos dispositivos móveis, que se multiplicam de forma ininterrupta desde os anos 2000, este modelo de governo não pode fechar os olhos para a realidade na qual está inserido, ignorando a desigualdade no acesso aos canais eletrônicos, geralmente chamada de lacuna digital (digital gap) ou divisão digital (digital divide). No Brasil, o contraste de oportunidades sociais é imenso e histórico. A desigualdade digital então apenas incorpora o nosso repertório de iniquidades. Diante disso, o Estado assumiria também um papel de democratizador do acesso, através de políticas de inclusão digital, a fim de ampliar o escopo da interação e ouvir vozes que não costumam ser ouvidas, de grupos que dificilmente têm chances reais de apresentar suas demandas na arena de debate político e, portanto, acabam alheias ao centro de alocação dos recursos. Estes contingentes marginalizados encontram na internet e nas políticas que dela se valem, uma oportunidade para dar o seu recado. Do contrário, se este aspecto fosse negligenciado, as disparidades de acesso se converteriam em desigualdade de influência política, resultando na formação de elites participantes que buscam somar ao patrimônio de alguns, mais um conjunto de benefícios. Regressaríamos ao ciclo de má-governança e geração de privilégios.

Especificamente quanto à implementação do governo eletrônico, a Organização das Naçôes Unidas apresenta cinco estágios de desenvolvimento, que sucedem diferentes níveis de abertura governamental. Primeiro, a fase emergente, representada pela simples presença on-line do governo, sem, contudo, apresentar dados relevantes sobre suas ações. Na segunda fase, as informaçôes e os dados governamentais (procedimentos, leis, regulações, relatórios e notícias) já estão disponíveis em 
sítios próprios e acessíveis, porém, sem interatividade, que diz respeito à terceira fase, na qual os portais permitem a realização de serviços on-line, como a obtenção de licenças (e-licensing) e o pagamento de tributos (e-taxes). Na quarta etapa, aumenta o nível de interação, de modo que a comunicação entre governo e povo é experimentada em vias recíprocas, e a maior parte das transações são feitas pela internet. No último momento, o governo está conectado caso responda adequadamente às necessidades dos cidadãos através do desenvolvimento de uma estrutura integrada. ${ }^{336}$

E a quantas anda o e-government no Brasil? Ainda é controversa a possibilidade de incluirmo-nos na seara das democracias digitais consolidadas, como o Reino Unido ou a Estônia. É certo, porém, que somos uma nação digital, a ver que, por exemplo, o número de linhas de celulares ativas, hoje em torno de 280 milhões, já se equipara à população brasileira. ${ }^{337}$ A quantidade de assinantes de banda larga fixa (27,17 milhões) é expressiva em termos globais. Não obstante essa grande massa digital, os governos no Brasil ainda não se tornaram um fornecedor à altura de informações públicas e oportunidades para o controle e participação social on-line. É inegável que tivemos evoluções importantes em termos de implementação das plataformas eletrônicas governamentais, porém, há muito espaço para melhoramentos, e a ausência de vontade política e de pressão por parte da sociedade fez com que regredíssemos em alguns aspectos.

É o que demonstra o índice de desenvolvimento do governo eletrônico, mensurado pela Organização das Nações Unidas (E-Government Development Index). Em 2005, o Brasil ocupava a 33a posição no tocante ao governo digital, dentre 193 países pesquisados, onze anos depois, em 2016, em queda-livre, o país chegou a 51 colocação. No quesito específico referente ao desenvolvimento de mecanismos de participação eletrônica (e-participação), o Brasil perdeu vinte posições em 10 anos. ${ }^{338}$ Com relação às plataformas de acesso à informação, um estudo da FGV-Rio, diagnosticando os sítios e ferramentas eletrônicas de transparência dos Estados e das capitais brasileiras, concluiu que existem deficiências graves no cumprimento da Lei de Acesso à Informação (Lei n. 12.527/2011) pelas entidades políticas,

336 UNITED NATIONS (DESA). E-Government Survey 2008. From e-Government to Connected Governance. United Nations, New York, 2008, p. 16.

337 BRIGATTO, Gustavo. Número de celulares no Brasil chega a 283,4 milhões em março. Valor Econômico. Maio 2005.

338 ONU. Department of Economic and Social Affairs. E-Government Knowledge Database. Disponível em: <https://publicadministration.un.org/egovkb/en-us/Data/Country-Information/id/24-Brazil >. Acesso em: 5 fev. 2018. 
sobretudo no tocante à transparência ativa, que representa a disponibilização, pelo Estado, de informaçôes e dados públicos, independentemente do requerimento de eventuais interessados. ${ }^{339}$ Tal constatação é reforçada pelo Índice de Dados Abertos, da ONG Open Knowledge Brasil, ao avaliar que o problema mais recorrente em relação à abertura de dados é a dificuldade de se trabalhar os dados, bem como a não disponibilização da base de dados completa para download, o que indica que os órgãos responsáveis pelo provimento das informações não têm compreensão de que a facilitação do processo de edição e manipulação dos dados representa parte importante da transparência. ${ }^{340}$

O que se vê, e agora de forma mais anedotal, é a predominância do caráter meramente informativo dos portais públicos, com poucas funcionalidades referentes à prestação de serviços e ainda menos chances de interação nos processos de tomada de decisão política. Mesmo assim, a quantidade de informações disponíveis não convola a qualidade dos dados apresentados, geralmente publicados em caráter não aberto e em linguagem extremamente técnica.

A considerar os diversos compromissos assumidos pelo Brasil, e o fato de sermos o berço de inovações deliberativas como o orçamento participativo, em 1989, não deveríamos estar nesta trajetória declinante. A título de exemplo, o Brasil foi um dos primeiros países a subscrever o Plano de Ação Nacional sobre dados abertos, fruto da participação na 66 a Assembleia Geral das Nações Unidas, que marcou o início da Parceria Governo Aberto (Open-Government Partnership), que hoje conta com mais de cem países. Além do mais, em 2015, o governo federal criou a Estratégia de Governança Digital (Decreto n. 8.638/2016, referente ao ciclo trienal de 2016-2019), definindo uma série de metas para a implementação da Política de Governança Digital, centrada em três alicerces: acesso à informação (dados abertos), participação em todo o ciclo de política pública e prestação de serviços.

Pois bem, encerrando os aspectos gerais sobre o ambiente institucional em tempos de democracia digital, não poderia me furtar à questão acerca dos potenciais efeitos do governo eletrônico, e das ferramentas proporcionadas pela tecnologia, no controle da corrupção e da gestão imoral da coisa pública.

Do ponto de vista teórico, é fácil perceber que a emergência das ferramentas digitais pode fortalecer a agenda anticorrupção, revolucionando os métodos de

339 MICHENER, G. Transparência local no Brasil: avaliando a aplicação da lei de acesso nos estados e nas grandes cidades. Rio de Janeiro: FGV, 2016.

340 OPEN KNOWLEDGE BRASIL; FGV DAPP. Índice de Dados Abertos para o Brasil. Abril 2017. Disponível em: <file://C:/Users/joaoplm/Downloads/IndiceDadosAbertosBrasil2017-1. pdf $>$. Acesso em: 21 maio 2018. 
prevenção e detecção de comportamentos ilícitos. Segundo a OCDE, estas ferramentas abrem uma janela de oportunidades para o desenvolvimento de uma visão mais holística na luta contra a corrupção, especialmente porque fornece bases mais igualitárias para o conhecimento e envolvimento das pessoas no processo de tomada de decisões políticas, impondo restrições sociais contundentes à captura de recursos públicos e à perpetuação de privilégios injustos.

Vários estudos lograram demonstrar uma sólida correlação entre o aprimoramento no nível de utilização dos mecanismos de e-government e o decréscimo subsequente nos níveis de percepção da corrupção (CPI). ${ }^{341}$ Ademais, pesquisa semelhante aplicada em território brasileiro encontrou impactos positivos do governo eletrônico no número de casos de improbidade administrativa nos municípios. ${ }^{342}$

Embora seja prematuro afirmar com certeza os motivos que justificam tal relação, é possível conjecturar alguns pontos de influência da governança eletrônica, cujos efeitos fazem se sentir nas oportunidades para corrupção. A uma, o e-gov reduz a interação entre agentes e o público em geral, isto é, elimina a intermediação inerente ao modelo racional burocrático no acesso a determinados serviços e bens públicos, o que, por conseguinte, eliminaria, em tese, o escopo do pagamento de propinas. Neste aspecto, a digitalização superporia o processo de desburocratização, permitindo o acesso e o controle direto do público sobre as ações governamentais. Pelo lado da demanda privada, a utilização das ferramentas eletrônicas serviria como rota auxiliar na avaliação de risco, nos programas de compliance das empresas, consoante aponta o Instituto de Governança de Basel. ${ }^{343}$ A duas, ao prover os cidadãos com maiores informações (se qualificadas), o e-gov remove significativamente a discricionariedade de agentes e o monopólio sobre decisóes políticas importantes, elevando o custo de transação dos acordos corruptos.

341 Através de coeficientes de correlação e análise regressiva, Veronika Linhartová, pesquisadora da Universidade de Pardubice (República Checa) demonstrou que o aumento de $1 \%$ no nível de governo eletrônico (E-Government Index) no período de 2003 a 2014 causou a redução do nível de corrupção (Î́ndice de Percepção da Corrupção), em até 0,14\%. (LINHARTOVÁ, Veronika. The role of e-government in mitigating corruption. Scientific papers of the university of pardubice. Series D, Faculty of Economics and Administration, 2017). No mesmo sentido, a respeito do impacto positivo que o e-government exerce sobre a corrupção: ANDERSEN, Thomas Barnebeck. Does e-government reduce corruption? Department of Economics, University of Copenhagen, 2007.

342 VIEIRA, James Batista: Transparência pública e corrupção nos municípios brasileiros: o impacto do governo eletrônico. Revista Democracia Digital e Governo Eletrônico, n. 6, 2012, p. 17.

343 Basel Institute on Governance. New perspectives in e-government and the prevention of corruption. Working paper series n. 23, 2017. 
Este último aspecto é reforçado consideravelmente pelos mecanismos modernos de gestão de dados em larga escala, o tal BigData, que permitem, ao combinar algoritmos e comparar diversas fontes de dados, identificar inconsistências ou falhas em determinado padrão de comportamento (assessing organizational behavior), como a ocorrência de fraudes em contratos públicos, restrições à competição, cartelização ou evasão fiscal. Além deste aspecto - de detecção e imputação de responsabilidade - o processamento desta infraestrutura de dados destrava um universo inteiramente novo no tocante a políticas públicas com potencial enorme de melhorar a qualidade do gasto público, e que possibilitam uma redistribuição igualitária.

É certo, porém, que toda novidade desperta inquietude. Pudera, vez que a internet é um território praticamente inexplorado em sua integralidade. Determinadas inovações e políticas orientadas pela tecnologia da informação e comunicação têm gerado debates acirrados sobre ética e efetividade. Neste sentido, ainda pesam controvérsias, por exemplo, sobre a utilização das chamadas criptomoedas, como o Bitcoin, Ethereum, Ripple, Litecoin e da tecnologia de registros em cadeia do Blockchain, na perspectiva da evolução do controle da administração pública. Conforme a Transparência Internacional, essas ferramentas são apontadas, por um lado, como potenciais canalizadoras de crimes transnacionais, como a lavagem de dinheiro e, por outro, como possíveis instrumentos em benefício da prevenção à corrupção, já que mantém registradas todas as transações no mundo digital, em acesso aberto e universal. ${ }^{344}$ Com efeito, há notícia de projetos desenvolvidos na Suécia, Honduras e Geórgia, que utilizam o blockchain no registro de propriedades, e nos Estados Unidos, para atos relativos ao exercício da cidadania. Poder-se-ia cogitar da criação de um blockchain anticorrupção que, através da transparência, imutabilidade e rastreabilidade das informações relativas a transações de ativos, dê suporte a um sistema integrado e aberto de informaçôes sobre a gestão financeira do setor público, de modo que todas as transaçōes que envolvam qualquer real oriundo do orçamento público, fiquem gravadas nas cadeias de informação compartilhada, facilitando, por conseguinte, os trabalhos de auditoria operacional.

O que impera ressaltar, enfim, é que a internet e o desenvolvimento da governança eletrônica não são panaceias para as falhas sistêmicas que acometem o sistema político e a sua propensão ao patrimonialismo. Volta-se, novamente, à questão da cultura como pressuposto de reforma. A abertura digital do espaço público

344 KOSSOW, Niklas; DYKES, Victoria. Linkages between blockchain technology and corruption issues: providing on-demand research to help fight corruption. Transparency International, 2018. 
(agora ciberespaço) não significa que os cidadãos irão automaticamente se embeber de um forte espírito cívico do qual jamais dispuseram. Assim, à oferta de dados abertos e de mais oportunidades de ação compartilhada entre governo e governado deve corresponder o real interesse político da sociedade, sob risco de apenas colocarmos o vinho velho em garrafa nova, transformando o e-government em mera política de marketing do governo. A advertência de Coleman é pertinente: o fator que determina se a abertura governamental e as ferramentas digitais servirão como força democratizadora é a cultura política na qual elas se desenvolvem. ${ }^{345}$

Claro, não se descarta a hipótese de que a nova arquitetura digital produza efeitos importantes na cultura política, levando à formação de uma população mais ciente de suas obrigações, mas, recorrendo à lição de Amartya Sem, ainda que empoderado, é necessário que o cidadão valorize a participação política e tenha vontade de exercê-la.

O direito de acesso à informação pública (transparência) é pressuposto e indicador do nível de participação social. Pressuposto porque, consoante assentam os professores de Harvard, Cass Sustein e Stephen Holmes, se direitos resultam de escolhas estratégicas sobre a melhor forma de alocar recursos públicos, as decisões sobre políticas públicas devem ser feitas por um administrador de forma tão aberta quanto possível para uma cidadania tão informada quanto possível. Quer dizer, a participação depende da qualidade e extensão da informação disponível. ${ }^{346}$ É indicador porque sem uma abertura adequada dos dados públicos, reduz-se o interesse do cidadão em se envolver nas questôes coletivas. Cada maximização de democracia ou possibilidade de participação requer que o número de pessoas (bem) informadas seja maior. Se tomarmos esta direção, o resultado não pode ser outro senão uma sociedade potencializada, capaz de atuar mais e melhor do que antes. ${ }^{347} \mathrm{E}$, se somente é possível exercer a vigilância sobre aquilo que se conhece, o trajeto ao accountability, seja na perspectiva da imputação de responsabilidade (prestação de contas), seja na ótica da performance governamental (responsividade), só é pavimentado na medida em que se desenvolvam a transparência e a participação cívica.

345 COLEMAN, Stephen. Can the internet strengthen democracy? Cambridge: Polity Press, 2017.

${ }^{346}$ HOLMES, Stephen. SUSTEIN, Cass R. The cost of rights. Nova York: W. W. Norton \& Company, 1999, p. 227.

347 SARTORI, Giovanni. Homo videns. La sociedad teledirigida. Buenos Aires: Alfaguara, 1998. 